(c) American Dairy Science Association, 2004.

\title{
Physicochemical and Kinetic Properties of Purified Sheep's Milk Xanthine Oxidoreductase
}

\author{
Mustapha Benboubetra, ${ }^{1}$ Abderahmene Baghiani, ${ }^{1}$ \\ Djebbar Atmani, ${ }^{2}$ and Roger Harrison ${ }^{3}$ \\ ${ }^{1}$ Laboratory of Applied Biochemistry, Department of Biology, \\ Faculty of Sciences, University Ferhat Abbas of Setif, Algeria \\ ${ }^{2}$ Laboratory of Biochemistry, Faculty of Life and Nature Sciences, \\ University of Bejaia, Algeria \\ ${ }^{3}$ Department of Biology and Biochemistry, University of Bath, UK
}

enzyme long known to be present in the bovine milk fat globule membrane (MFGM) (Patton and Keenan, 1975). Because of this ready availability, XOR has been studied for over $100 \mathrm{yr}$ (Massey and Harris, 1997), and its enzymology is well characterized (Bray, 1975; Hille, 1996). It comprises 2 subunits $\left(M_{r} 150,000\right)$, each of which contains one flavin adenine dinucleotide, one $\mathrm{Mo}$, and $2 \mathrm{Fe}_{2} \mathrm{~S}_{2}$ redox centers. The enzyme occurs in 2 interconvertible forms, dehydrogenase (XDH, EC 1.1.1.204) and oxidase (XO, EC 1.1.3.22), both of which reduce molecular oxygen to the reactive oxygen species (ROS), superoxide anion and hydrogen peroxide. XDH, but not $\mathrm{XO}$, reduces $\mathrm{NAD}^{+}$.

The generally accepted physiological role of XOR is in purine catabolism, where it catalyzes the oxidation of hypoxanthine to xanthine and xanthine to uric acid, with concomitant reduction of $\mathrm{NAD}^{+}$or molecular oxygen (Bray, 1975). Nevertheless, the enzyme has a somewhat specialized distribution, being especially rich in endothelial and epithelial cells, and other functions have been sought, particularly those involving its generation of ROS (Harrison, 2002).

Together with the less-studied rat liver enzyme (Amaya et al., 1990), which has very similar properties, bovine milk XOR has provided a basis for discussions of XOR in humans. However, human milk XOR has surprisingly low XO activity (Abadeh et al., 1992; Sanders et al., 1997), resulting from its low content of molybdenum, which is less than 5\% theoretical (Godber et al., 1997; Bray et al., 1999). This low enzymatic activity raises questions about the physiological role of human XOR (Harrison, 1997) and the potential for posttranslational activation in vivo. Goats' milk XOR has recently been shown to have similarly low XO activity and Mo content (Atmani et al., 2004), albeit a little higher than that of the human enzyme, and it was of interest to examine XOR from other mammals. We now describe, for the first time, purification and characterization of XOR from sheep's milk.
Received August 15, 2003.

Accepted October 15, 2003.

Corresponding author: M. Benboubetra; e-mail: benboubetra@ yahoo.co.uk. 


\section{MATERIALS AND METHODS}

\section{Purification of Sheep's Milk XOR}

Xanthine oxidoreductase was purified from fresh sheep's milk by ammonium sulphate fractionation, followed by affinity chromatography on heparin and ionexchange fast protein liquid chromotagrpahy, essentially as described for bovine (Godber et al., 2000), human (Sanders et al., 1997) and goats' milk (Atmani et al., 2004). In a minor modification, $10 \mathrm{mM}$, rather than $5 \mathrm{~m} M$ dithiothreitol was added to the cream.

Concentration of enzyme was determined from the UV-visible spectrum by using an absorption coefficient of $36 \mathrm{mM}$ subunit ${ }^{-1} \mathrm{~cm}^{-1}$ at $450 \mathrm{~nm}$ (Bray, 1975). Protein concentrations were determined as described by Bradford (1976).

The oxidase content of XOR was determined by measuring the rate of oxidation of xanthine to uric acid spectrophotometrically at $295 \mathrm{~nm}$, using an absorption coefficient of $9.6 \mathrm{mM} \mathrm{cm} \mathrm{cm}^{-1}$ (Avis et al., 1956). Assays were performed at $25 \pm 0.2^{\circ} \mathrm{C}$ in air-saturated $50 \mathrm{mM}$ $\mathrm{Na} /$ bicine buffer, $\mathrm{pH} 8.3$, containing $100 \mu M$ xanthine. The sum of oxidase and dehydrogenase contents was determined as above but in the presence of $0.5 \mathrm{mM}$ $\mathrm{NAD}^{+}$.

Molybdenum content of purified XOR was determined by a modification (Atmani et al., 2004; Baghiani et al., 2003) of the colorimetric procedure of Hart et al., (1970).

\section{Steady-State Kinetic Studies}

With xanthine as reducing substrate, urate was determined as described above for determination of oxidase plus dehydrogenase content of XOR. $1 \mathrm{U}$ is defined as $1 \mu$ mole of urate produced per minute. With $\mathrm{NADH}$ as reducing substrate, $\mathrm{NADH}$ utilization was followed at $340 \mathrm{~nm}$, in air-saturated $50 \mathrm{~m} M$ sodium phosphate buffer, $\mathrm{pH} 7.2$, at $25 \pm 0.2^{\circ} \mathrm{C}$, by using an absorption coefficient of $6.22 \mathrm{~m} M^{-1} \mathrm{~cm}^{-1}$ (Horecker and Kornberg, 1948). $1 \mathrm{U}$ is defined as $1 \mu$ mole of $\mathrm{NADH}$ consumed per minute.

\section{Desulfuration and Sulfuration of XOR}

Purified sheep's milk XOR was converted to its desulfo-form by incubation with KCN (Massey and Edmondson, 1970; Godber et al., 2000). Desulfo-XOR or native enzyme were (re)sulfurated by incubation with methyl viologen and sodium sulfide in a modification (Godber et al., 2000; Baghiani et al., 2003) of the procedure described by Wahl and Rajagopalan (1982).

\section{SDS-PAGE}

SDS-PAGE was performed on a Bio-Rad Protean II mini-gel apparatus according to the method of Laemmli (1970), using a 5\% concentrating gel and $10 \%$ separating gels. Samples and standards of known molecular weights (MW-SDS-200 Kit, Sigma) were run at 100 (stacking gel) and $200 \mathrm{~V}$ (running gel). Gels were stained for protein with Coomassie brilliant blue.

\section{RESULTS}

Five separate purifications yielded $22.6 \pm 3.3 \mathrm{mg}$ (mean \pm SD) of XOR per liter of sheep's milk. Purified enzyme showed a characteristic UV-visible spectrum (Figure 1), with $A_{280} / A_{450}$ (protein to flavin, PFR) ratio of $5.34 \pm 0.24$ (mean $\pm \mathrm{SD}, \mathrm{n}=5$ ), indicating a high degree of purity (Bray, 1975). The PFR values for bovine, human, and sheep's milk enzymes prepared in parallel were very similar (Table 1).

Enzyme purity was confirmed by SDS-PAGE, which showed a single major protein band with $\mathrm{M}_{\mathrm{r}}$ approximately 150,000 (Figure 1, inset). Around 25\% of the purified enzyme was in the dehydrogenase form.

Xanthine oxidase activity of purified sheep's milk XOR was $0.69 \pm 0.04 \mathrm{U} / \mathrm{mg}$ of protein, compared with respective $V_{\max }$ values of $1.83 \pm 0.02,0.06 \pm 0.01$, and $0.27 \pm 0.01 \mathrm{U} / \mathrm{mg}$ of protein for bovine, human, and goats' milk, similarly prepared in the present study (Table 2). The $\mathrm{K}_{\mathrm{m}}$ values for XOR from sheep's, human, and goats' milk were similar, being some threefold higher than that of the bovine milk enzyme (Table 2). The $\mathrm{V}_{\max }$ and $\mathrm{K}_{\mathrm{m}}$ values for NADH oxidation were similar for all 4 species (Table 2).

The molybdenum content of purified sheep's milk $\mathrm{XOR}, 0.18 \pm 0.04$ atoms per subunit, is compared with those previously reported for enzymes of other species in Table 1.

As shown in Table 3, incubation of the sheep's milk enzyme with KCN led to total loss of XO activity, consistent with its conversion to desulfo-enzyme. Either desulfo- or native XOR could be resulfurated, whereby the native enzyme regained $173 \%$ of its original xanthine oxidase activity. Purified bovine and human milk XOR behaved similarly, demonstrating the presence of significant contents of desulfo-form in preparations of native enzyme from all 3 species.

\section{DISCUSSION}

Xanthine oxidoreductase has been purified, for the first time, from sheep's milk. The purification procedure involved chromatography on heparin, as described previously for the bovine (Godber et al., 2000), human (Sanders et al., 1997), and goats' milk (Atmani et al., 


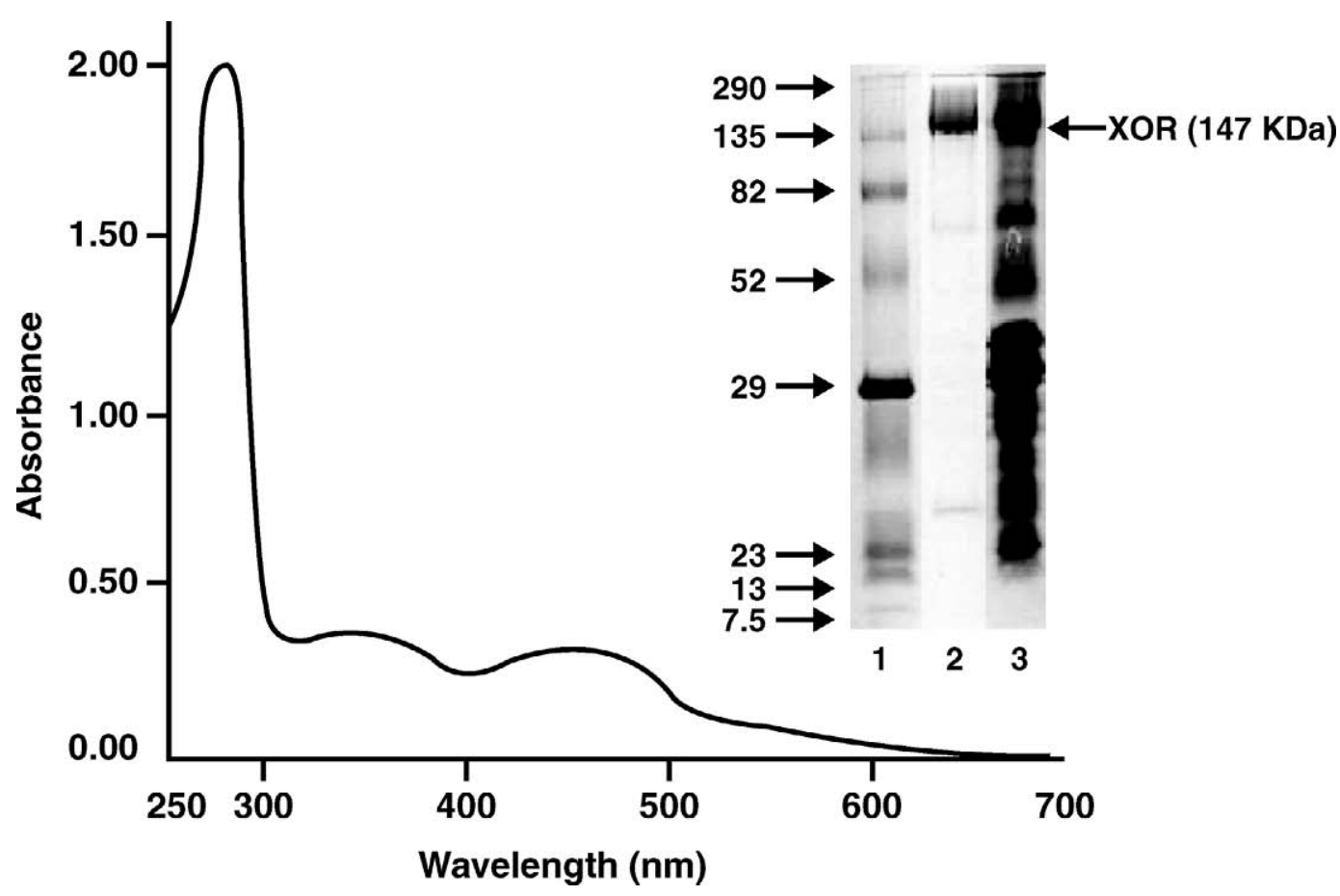

Figure 1. Ultraviolet-visible spectrum of purified sheep milk xanthine oxidoreductase (XOR) showing the three classic characteristic maxima at 280, 350, and $450 \mathrm{~nm}$ and SDS-PAGE (10\%) of sheep milk XOR. Lines: $2=$ pure sheep milk XOR; $3=$ sheep XOR sample before heparin affinity chromatography; and 1 = molecular weight markers (myosin, 290,000; $\beta$-galactosidase, 135,000; albumin, 82,000; ovalbumin, 53,000; carbonic anhydrase, 29,500; trypsin inhibitor, 23,500; $\beta$-lactalbumin, 13,000; and aprotinin, 7500).

2004) enzymes. The UV-visible spectrum (Figure 1) was characteristic of XOR and showed a PFR ratio close to 5.0 , generally accepted as a criterion of purity (Bray, 1975; see also Atmani et al., 2004). Like other XOR, freshly purified sheep's milk enzyme showed a single band on SDS-PAGE corresponding to a subunit of approximately $150 \mathrm{kDa}$. Traces of degradation bands appeared on storage (cf. Abadeh et al., 1992; Atmani et al., 2004).

The specific XO activity of purified sheep's milk XOR was found to be $0.69 \mu \mathrm{mol}$ of urate $\mathrm{min}^{-1} \mathrm{mg}^{-1}$. This can be compared with corresponding values for the purified human, goats', and bovine milk enzymes $(0.06,0.27$, and $1.83 \mu \mathrm{mol}$ of urate $\mathrm{min}^{-1} \mathrm{mg}^{-1}$, respectively), which have been explained (Atmani et al., 2004) in terms of their molybdenum contents $(0.03,0.09$, and 0.55 atoms per subunit, respectively). The molybdenum content of sheep's milk XOR was shown here to be 0.18 atoms per subunit, which is roughly consistent with its specific activity. It is worth noting that, although xanthine is reduced directly at the Mo site (Bray, 1975), molybdenum content is not alone in determining $\mathrm{XO}$ activity. Xanthine oxidoreductase contains variable amounts of 'desulfo' enzyme, which contains molybdenum but is inactive because of 'replacement' of an $\mathrm{Mo}=\mathrm{S}$ grouping by $\mathrm{Mo}_{0}=\mathrm{O}$ (Gutteridge et al., 1978; Wahl and Rajagopa-

Table 1. Kinetic parameters for xanthine oxidation and NADH oxidation of xanthine oxidoreductase (XOR) purified from sheep's, human, goats', and cows' milks. ${ }^{1}$

\begin{tabular}{lllll}
\hline & $\begin{array}{l}\text { Sheep's milk } \\
\text { XOR }\end{array}$ & $\begin{array}{l}\text { Human milk } \\
\text { XOR }\end{array}$ & $\begin{array}{l}\text { Goats' milk } \\
\text { XOR }\end{array}$ & $\begin{array}{l}\text { Cows' milk } \\
\text { XOR }\end{array}$ \\
\hline $\begin{array}{llll}\text { Xanthine oxidation } \\
\text { K }(\mu M)\end{array}$ & $7.14 \pm 0.9$ & $7.74 \pm 0.06$ & $6.33 \pm 0.08$ & $2.15 \pm 0.05$ \\
Vmax & $0.69 \pm 0.04$ & $0.06 \pm 0.01$ & $0.27 \pm 0.01$ & $1.83 \pm 0.02$ \\
NADH oxidation & & & & \\
$\mathrm{K}_{\mathrm{m}}(\mu M)$ & $2.19 \pm 0.10$ & $2.52 \pm 0.08$ & $4.12 \pm 0.06$ & $2.74 \pm 0.12$ \\
Vmax & $0.21 \pm 0.04$ & $0.29 \pm 0.03$ & $0.27 \pm 0.04$ & $0.25 \pm 0.05$ \\
\hline
\end{tabular}

${ }^{1}$ Values are expressed as mean $\pm \mathrm{SD}(\mathrm{n}=5)$. $\mathrm{V}_{\max }$ values are in units $(1 \mathrm{U}=\mu$ mole of urate production or NADH utilization) per mg of enzyme (see Materials and Methods Section). 
Table 2. Contents of Mo in xanthine oxidoreductase (XOR) purified from sheep, goat, cow, and human milk.

\begin{tabular}{lcccc}
\hline & Sheep & Goat & Cow & Human \\
\hline PFR $^{1}$ & $5.35 \pm 0.24$ & $5.20 \pm 0.12$ & $5.28 \pm 0.17$ & $5.39 \pm 0.23$ \\
Mo content, atoms/subunit & $0.183 \pm 0.041$ & $0.091 \pm 0.050$ & $0.548 \pm 0.050$ & $0.029 \pm 0.006$ \\
Demolybdo form, \% & 81.7 & 90.9 & 45.2 & 97.1 \\
\hline
\end{tabular}

${ }^{1} \mathrm{PFR}=$ Protein to flavin ratio. Molybdenum contents are expressed as means $\pm \mathrm{SD}(\mathrm{n}=4)$.

lan, 1982). Consequently, ratios of Mo contents are not directly comparable to ratios of xanthine oxidase activities. In fact, sulfuration of purified sheeps' milk XOR resulted in an increase in specific activity of $73 \%$ (Table 3 ). Assuming that resulfuration is only $50 \%$ efficient (Nishino et al., 1983), this translates into a desulfocontent of approximately $60 \%$. While this value is far from precise, it represents a significant component.

Corresponding values for bovine and human milk XOR, calculated from the data in Table 3 are approximately 40 and $70 \%$ desulfo-content, respectively. As shown in Table 3, treatment of XOR with KCN led to complete loss of xanthine oxidase activity, which could be restored by sulfuration under the same conditions as for the native enzymes. That the restored activity was, in all 3 cases, less than that generated by sulfuration of native enzyme can be explained in terms of inactivation during incubation with KCN.

In contrast to $\mathrm{XO}$ activity, $\mathrm{NADH}$ oxidase activity of sheep's milk XOR $\left(0.21 \mu\right.$ mole of NADH consumed min $^{-}$ ${ }^{1} \mathrm{mg}^{-1}$ ) was similar to those previously determined (Atmani et al., 2004) for human, goats', and cows' milk enzymes $(0.29,0.27$, and $0.25 \mu$ mole of $\mathrm{NADH}$ consumed $\mathrm{min}^{-1} \mathrm{mg}^{-1}$, respectively). This is entirely consistent with the fact that NADH oxidase activity of XOR involves donation of electrons to the flavin adenine dinucleotide site and is not directly influenced by Mo content (Bray, 1975).

An obvious question concerns the physiological relevance of XOR with low XO activity. In the case of the milk fat globule membrane, XOR has long been recognized as a major protein component (Patton and Keenan, 1975) and has been implicated in the process of milk lipid secretion (Mather and Keenan, 1998; Keenan, 2001). Very recently, McManaman and colleagues
(2002, 2003) provided evidence that XOR mediates interaction between butyrophilin (in the apical membrane of the secretory cell) and adipophilin (on the lipid droplet) during the envelopment of cytoplasmic lipid droplets by the apical membrane. The involvement of XOR in this process was further supported by Vorbach et al. (2002), who observed defective lactation in XOR mice and demonstrated, by electron microscopy, that XOR is necessary for envelopment of lipid droplets by the secretory cell membrane.

Interestingly, the latter authors provided evidence that XOR participates in milk secretion by virtue of its protein structure rather than its enzymatic activity, possibly explaining the predominance of 'inactive' XOR in human, goat, and sheep milks. What, then, is the role of XO activity in this context? A possible answer lies in microbicidal activity of MFGM in the neonatal gut, involving XOR-catalyzed reduction of nitrite yielding nitric oxide and peroxynitrite (Hancock et al., 2002; Harrison, 2002; Atmani et al., 2004). Such activity clearly requires active enzyme, and particularly an active molybdenum site, which is essential for nitrite reduction (Godber et al., 2000). It is noteworthy that, in the first few weeks postpartum, both XO (Brown et al., 1995) and nitrite reductase (Stevens et al., 2000) activities of human milk are much higher than in subsequent fractions, from which enzyme is commonly purified. In some cases, XO activity was seen to rise to a peak immediately after birth (Brown et al., 1995). Throughout these variations in enzymatic activity, XOR protein levels remained relatively constant, suggesting posttranslational activation-deactivation. It is an attractive idea that the process of milk lipid secretion depends solely on XOR protein, which is later activated in order to fulfill a microbicidal function in the neonate.

Table 3. Total specific activity ( $\mu \mathrm{mol}$ of urate/min per $\mathrm{mg}$ ) of native and potassium cyanide (KCN)-inactivated sheep's, bovine, and human milk zanthine oxidoreductase (XOR) before and after resulphuration.

\begin{tabular}{llllll}
\hline & \multicolumn{2}{c}{ Before resulphuration } & & \multicolumn{2}{c}{ After resulphuration } \\
\cline { 2 - 3 } \cline { 6 - 7 } Enzyme sample & Native & KCN-treated & & Native & KCN-treated \\
\hline Sheep's milk XOR & $0.6347 \pm 0.0451$ & ND $^{1}$ & & $1.0892 \pm 0.0387$ & $0.8654 \pm 0.1145$ \\
Bovine milk XOR & $2.1107 \pm 0.0245$ & ND & & $2.8935 \pm 0.0874$ & $2.1875 \pm 0.0637$ \\
Human milk XOR & $0.0644 \pm 0.0127$ & ND & & $0.1282 \pm 0.0295$ & $0.0896 \pm 0.0764$ \\
\hline
\end{tabular}

${ }^{1} \mathrm{ND}=$ Not detectable. 
This could be seen as fulfilling an evolutionary advantage by sparing metabolically expensive processes (e.g., incorporation of Mo?) until required. While highly speculative, such ideas suggest experimental investigation.

\section{ACKNOWLEDGMENTS}

This work was supported by the Algerian Ministry of Higher Education and Scientific Research (MERS) and from the Algerian Agency for the Development of Research in Health (ANDRS). We would like to thank R. Eisenthal and B. Godber for critical discussion.

\section{REFERENCES}

Abadeh, S., J. Killacky, M. Benboubetra, and R. Harrison. 1992 Purification and partial characterisation of xanthine oxidase from human milk. Biochim. Biophys. Acta 1117:25-32.

Amaya, Y., K. I. Yamazaki, M. Sato, K. Noda, T. Nishino, and T. Nishino. 1990. Proteolytic conversion of xanthine dehydrogenase from NAD-dependant type to the $\mathrm{O}_{2}{ }^{-}$dependant type. J. Biol. Chem. 265:14170-14175.

Atmani, D., M. Benboubetra, and R. Harrison. 2004. Goats' milk xanthine oxidoreductase is grossly deficient in molybdenum. J. Dairy Res. 71:7-13.

Avis, P. G., F. Bergel, R. C. Bray, D. W. F. James, and K. V. Shooter. 1956. Cellular constituents, the chemistry of xanthine oxidase. Part II: The homogeneity of crystalline metalloflavoprotein fractions. J. Chem. Soc. (Perkins I) 1212-1219.

Baghiani, A., R. Harrison, and M. Benboubetra. 2003. Purification and partial characterization of camel milk xanthine oxidoreductase. Arch. Physiol. Biochem. (accepted).

Bradford, M. M. 1976. A rapid and sensitive method for the quantitation of microgram quantities of protein. Anal. Biochem. 72 $248-254$.

Bray, R. C. 1975. Molybdenum iron-sulfur flavin hydroxylases and related enzymes. Pages 299-419 in The Enzymes. Vol. XII, 3rd ed. P. D. Boyer, ed. Academic Press, New York, NY.

Bray, R. C., D. Lowe, B. Godber, R. Harrison, and R. Eisenthal. 1999. Properties of xanthine oxidase from human milk: The enzyme is grossly deficient in molybdenum and substantially deficient in iron sulphur centres. Pages $775-778$ in Flavins and Flavoproteins, Proc. 13th Int. Symp. Konstanz, Germany. S. Ghisla, P. M. H. Kroneck, P. Macheroux, and H. Sund, eds. Agency for Scientific Publications, Berlin, Germany.

Brown, A-M., M. Benboubetra, M. Ellison, D. Powell, J. D. Reckless, and R. Harrison. 1995. Molecular activation-deactivation of xanthine oxidase in human milk. Biochim. Biophys. Acta 1245:248-254.

Godber, B., S. Sanders, R. Harrison, R. Eisenthal, and R. C. Bray. 1997. $>95 \%$ of xanthine oxidase in human milk is present as demolybdo form lacking molybdopterin. Biochem. Soc. Trans. 25:519S.
Godber, B. L. J., J. J. Doel, G. P. Sapkota, D. R. Blake, C. R. Stevens, R. Eisenthal, and R. Harrison. 2000. Reduction of nitrite to nitric oxide catalysed by xanthine oxidoreductase. J. Biol. Chem. 275:7757-7763.

Gutteridge, S., S. J. Tanner, and R. C. Bray. 1978. Comparison of the molybdenum centres of native and desulpho xanthine oxidase. Biochem. J. 175:887-897.

Hancock, J. T., V. Salisbury, M. C. Ovejero-Boglione, R. Cherry, C. Hoare, R. Eisenthal, and R. Harrison. 2002. Anti-microbial properties of milk: Dependence on presence of xanthine oxidase and nitrite. Antimirob. Agents Chemother. 46:3308-3310.

Harrison, R. 1997. Human xanthine oxidoreductase: In search of a function. Biochem. Soc. Trans. 25:786-790.

Harrison, R. 2002. Structure and function of xanthine oxidoreductase: Where are we now? Free Rad. Biol. Med. 33:774-797.

Hart, L. I., M. A. McGartoll, H. R. Chapman, and R. C. Bray. 1970. The composition of milk xanthine oxidase. Biochem J. 116:851-864.

Hille, R. 1996. The mononuclear molybdenum enzymes. Chem. Rev. 96:2757-2816.

Horecker, B. L., and A. Kornberg. 1948. The extinction coefficients of the reduced band of pyridine nucleotides. J. Biol. Chem. 175:385-390.

Keenan, T. W. 2001. Milk lipid globules and their surrounding membrane: A brief history and perpectives for future research. J. Mammary Gland Biology Neoplasia 6:365-371.

Laemmli, U. K. 1970. Cleavage of structural proteins during the assembly of the head of bacteriophage T4. Nature 227:680-685.

Massey, V., and Edmondson, D. 1970. On the mechanism of inactivation of xanthine oxidase by cyanide. J. Biol. Chem. 245:65956598 .

Massey, V., and C. M. Harris. 1997. Milk xanthine oxidoreductase: The first one hundred years. Biochem. Soc. Trans. 25:750-755.

Mather, I. H., and T. W. Keenan. 1998. Origin and secretion of milk lipids J. Mammary Gland Biology Neoplasia 3:259-273.

McManaman, J. L., C. A. Palmer, R. M. Wright, and M. C. Neville. 2002. Functional regulation of xanthine oxidoreductase expression and localization in the mouse mammary gland: Evidence of a role in lipid secretion. J. Physiol. 545:557-569.

McManaman, J. L., and M. C. Neville. 2003. Mammary physiology of milk secretion. Adv. Drug Del. Res. 55:629-641.

Nishino,T., C. Usami, and K. Tsushima. 1983. Reversible interaction between sulfo and desulfo xanthine oxidase in a system containing rhodanese, thiosulfate and sulfhydryl reagent Proc. Natl. Acad. Sci. USA 80:1826-1829.

Patton, S., and T. W. Keenan. 1975. The milk fat globule membrane. Biochim. Biophys. Acta 415:273-309.

Sanders, S. A., R. Eisenthal, and R. Harrison. 1997. Oxidation of NADH by human xanthine oxidoreductase: Generation of superoxide anion. Eur. J. Biochem. 245:541-548.

Stevens, C. R., T. M. Millar, J. G. Clinch, J. M. Kanczler, T. Bodamyali, and D. R. Blake. 2000. Antibacterial properties of xanthine oxidase in human milk. Lancet 356:829-830.

Vorbach, C., A. Scriven, and M. R. Capecchi. 2002. The housekeeping gene xanthine oxidoreductase is necessary for milk fat droplet enveloping and secretion: gene sharing in the lactating mammary gland. Genes Develop. 16:3223-3235.

Wahl, R. C., and K. V. Rajagopalan. 1982. Evidence for the inorganic nature of the cyanolyzable sulfur of molybdenium hydroxylases. J. Biol. Chem. 257:1354-1359. 